\title{
Writing It: Some Observations on the Poetics of Territoriality
}

I'll start by saying some things that I pretty much believe: that, in my experience, writing, especially but not only the writing of poetry, involves chasing after an object that is as real to the writer as it is undefined and elusive-an "it." And that this something, this fluttering scrim, this structural "it," once sprayed with words, assumes a shape that dissolves almost at the moment one apprehends it, leaving behind its shadow-outline, which looks a lot like the outline of a self made momentarily manifest by the poem. And that in really exciting poems this process is accelerated, so that the it-play between substance and emptiness, selves and specters, becomes the mode by which we make contact with thought and feeling constructing and dismantling us across time. I really mean it. When Ashbery, in "Pyrography," opens by saying "Out here on Cottage Grove it matters," you've got to feel that Ashbery's "it" is tangled as much with the invoked presence of "here" as with the dizzy, dislocated problem of being on, and writing from, the "outs," the "out-here"; and that the need to specify "Cottage Grove," a place named of two evocatively idealized place names, must in some way indicate a certain anxiety about its opposite, about losing the farm, about oblivion; and that "it" is therefore made of the pastness of the present, the presence of pastness, matter and immateriality equally; and that "it" is the matter and, indeed, "it matters." But I have an inkling, or a bias, that this "it," this anonymous identity that is on glorious occasion the poem flickering across an instance of writing, is now and again a troubling object to those who teach and study literature.

If I'm wearing my poet's smock here for a moment, the way it often feels in this garment is that the line in the sand between creative writing and literature concerns our respective stances towards "it," and, further, towards "writing it." "And lo," wrote Frost, who I'm told you critics rarely teach anymore, "a ripple / Shook whatever it was lay there at bottom, / Blurred it, blotted it out. What was that whiteness? / Truth? A pebble of quartz? For once then, something." Or as Coleridge, who did okay at transgressing the 
boundary between creative writing and criticism, wrote in every high school student's least favorite poem, apropos some "it" he "beheld" in the sky,

At first it seemed a little speck, And then it seemed a mist; It moved and moved, and took at last A certain shape, I wist.

A speck, a mist, a shape, I wist! And still it neared and neared: As if it dodged a water sprite, It plunged and tacked and veered.

That is what "it" does when one really writes it, writes the hell out of it: it plunges and tacks and veers.

"Presence" and "authorship" are constructs that have taken a far more severe spanking from literary critics than from poets, and I'm bound to report that I don't completely believe you when you deploy these words as if they were the raw materials of abomination, because I know that you write books yourselves, and some of those books must have consumed years of hard labor. I don't know any writer who doesn't embrace his or her own authorship, even if being an author can leave one feeling humiliated and filled with self-recrimination. It's hard to be present on the page or in the class, but personally, presence is what I want, even if it's not what I want at this moment. I want to read, and God knows, to write the poem that produces the sensation of the immediate presence of an other that had been unavailable to me without the poem; I want, in that way, the poem that makes me feel present to myself. I can't imagine I'm alone, especially in a room filled with people who have read more than I have. So what's the problem? Is the problem that presence is an impossibility? Why is that a problem? How long ago was it that striving after impossible ideals was thought to be a humanizing impulse? I like being an author. It feels remotely honest to me. It's not unrelated to accepting a modicum of responsibility for the space I'm taking up on the planet. Every author I know knows that "the author" as authorizing agent, as the sole possessor of his or her network of meaning, is dead-has never not 
been dead. Big deal. It's just that critics might want to consider that sometimes those of us on the creative writing side of things get a little wounded by your zeal in reminding us of it - that sometimes, the rallying cry of the death of the author can sound a touch too gleeful.

This is a way of saying that what writers like me believe lies at the root of our divergence from writers like you is this: we tend to need to hold in ambivalent high regard the set of metaphysical precepts that we see you claiming to reject. These precepts include the entire list of dirty words that are uttered by the invisible presence of the author: words like imagination, and emotion, and empathy, and self, and subjectivity, and beauty, and soul, and-let's go for it - truth. I, myself, regard all these terms with plenty of skepticism, and I have no problem agreeing that they are often wielded by all manner of liars and despoilers and demagogues. But we are all of us bad and irresponsible critics if we can't distinguish the appeal to metaphysics made by Pat Buchanan from that made by T.S. Eliot - if we say that because a similar set of underlying assumptions appears to be in play, that both men represent predictable outcomes of the same phenomenon. That's just very blunt and fearful thinking, and even though the example is a caricature, I don't think it's all that far off.

And it's also, of course, a symptom of the reluctance to make detailed and vulnerable qualitative judgments, which you know is one of the major complaints that creative writers have against critics: our sense that our work is judged on broad categorical standards that lack the flexibility to address individual poems as individuals. Hence popular culture - which I think we can agree tends to hollow out the imprints of individual "authorship" and to foreground, instead, the processes of social codification, thereby presenting rather stark and simplified evidence of the truths that theory proffers - made its appeal known to a new generation of scholars who were not only equipped with theory but who, like me, had grown up enamored of pop culture and who were tired of being made to feel guilty about their enthusiasms. So now we could read Lacan in "The Terminator" and Kristeva in "Dallas" and before long the anti-canonical frenzy in English departments began to spatter syllabi with required reading of what we writers have no problem calling third rate novels and poems by what we writers have no 
problem calling minor practitioners, or hacks. A bad poem makes itself so much more readily available to absorption by critical language than a good poem, which has the disarming tendency, as Coleridge suggested earlier, to "plunge and tack and veer."

Please correct me if I'm wrong; or don't: But the perception reigns among poets that in the past few academic generations the smartest and most agile and most passionate critics turned their attentions en masse from canonical literature to theorizing, dragging along in their wake a whole lot of sturdy, less agile thinkers. Theory, it seems, is where both the fun and the money are to be had. I'll be honest. As far as I can tell, the wholesale turn to theory, accompanied by a turning against humanism, has had mostly disastrous effects for poetry and criticism alike-disastrous in the small, and local sense; there's little doubt in my mind that with or without criticism, with or without creative writing workshops, the rare miraculous event that is a beautiful and true poem will persist. Certainly theory is what most alienates us from each other in the academy, unless we are at one of those places, like Buffalo, where it seems the poets and theorists are locked in an enduring mutually reinforcing swoon. How happy for those Western New York radicals. On the other hand, an MFA program like the Writers' Workshop, which has made itself available for no end of chiding from those in the theoretical loop, has instead become something of a repository for humanist thinking and action in an intellectual environment that reproduces a well-rehearsed hostility towards humanism. It's a hostility that I find perverse. For all the grandiosity that is bound up in the critique of humanism, for all the blush of liberation that one experiences in dismissing humanism-not entirely wrongly - as the self-serving philosophical and cultural arm of brutal ideological forces, it's got to be worth asking: Whose interests are served by the rejection of humanism? Is a clammy adherence to the hypocrisies of humanism really the problem in, say, the Shell oilfields of Nigeria or the Freeport McMoran gold mines in Irian Jaya? Is its obsolete humanism really the problem with contemporary poetry? I find something chilling in the desire to vacate the poem of the human subject, I find in it an anorexic and gratuitous idealization of the prospect of having clean hands, of being purified, and since I don't have the academic credentials to demand more of myself, I'm going to continue my devotion to 
poetry as a means of instructing me to develop a more fully fuckedup and humane soul, devotion to a poetry that works to erode, rather than to celebrate, the calloused sensibility.

I want my students to figure out what it means to "read like a poet." My feeling is that it involves a primary dedication to the material processes of the poem-its diction and syntax and imagery and rhythm and structural actions and inactions. I'm persuaded by the notion that the techniques of a poem are the most precise analog we have available for the techniques of feeling and thinking. I like to sit with a small group of people whose attention is absorbed along with mine in the marks on the page in front of us, and to try as best as possible to describe, together, the field of responsiveness generated by a word before moving on to the next word, and then to try to feel how that word alters the effect produced by the previous one. It's a little like that old exercise your shrink might have given you, to chew each bite of your food a hundred times in order to really taste it. How many of us really tasted our food tonight? What does it mean, not just individually but spiritually and socially, not to really have tasted our food? What's wrong with us? I think it's something that poems can fleetingly correct, if they are allowed to do their work on us without us restlessly and insecurely swallowing first.

Although I'm doing my best to give this talk as forthrightly as possible in the limited language at my disposal, it really doesn't matter to me if these few ideas I'm working out can easily be poked full of holes and shown up. What ideas can't be? I'm not interested in ideas per se. "Ideas" tend to be among the main culprits in protecting ourselves from the emotional claims of the experiential realm-ideas tend, simply put, to be falsifications of feeling. Last week I met with a quite brilliant young student here and found myself saying, in trying to explain why it seemed to me that the verbal and rhythmic and hence emotive vigor had slackened in a particular passage of her poem, that she was trying to be too smart, too summarily apt, at that moment in the poem. And walking out of the building with her I admitted that I don't want to be smart in my poems, I want to be stupid - stupid, that is, by disarming my habitual intellectualizing reflexes, by not pretending to master the emotional and spiritual mess of the inner and outer worlds through cleverness or ironizing gestures or generalizations or metaphoric 
effusions. As a reader or writer, I want, I need the act of the poem to help me, however provisionally, to "reclaim radical innocence," in Yeats' words. You may not share my values, you may find them politically or pedagogically suspect. And fair enough. But I'm not asking for permission, just as poems ought not to ask critics for permission, just as none of my students has to ask my permission to do whatever they want to do with themselves on the page, just as I'm not dictating to you that you try to reclaim radical innocence in your own reading and teaching. "Often," Duncan famously said, "I am permitted to return to a meadow." The only way that I know that there's a pedagogical problem in English departments is that, since beginning to teach graduate students in 1992, I've met hungry and dedicated students from all manner of institutions around the country who want permission, themselves, to read poems with emotive and experiential and technical rigor - not with the theoretical rigor that theorists so rigorously demand. So I'm admitting my agenda to you. I'm trying to position fantastically gifted, poetry-adoring young writers to recognize for themselves that poems are not theoretical occasions. I don't know of any more defeated stance than the one that claims there is no experience that hasn't already been theorized.

That's why I feel compelled to argue, without much pleasure, that while English departments and creative writing programs have plenty to offer each other, theoretically, under the current circumstances the blending of our impulses ought probably, and sadly, to be resisted. English departments have come to respond forcefully only to poetry that cow-tows to critical fashion. And there have always been plenty of poets willing to perform that degraded task. For a long time, they were the sycophants of the New Critics, turning out verse on the proper themes in the proper modes, and their heirs are among those who, enfeebled by tenure and institutional rewards, still constitute the dwindling legions of what everyone dismissively calls the "mainstream." Now, of course, the situation has changed; and the ones who are blowing kisses to the academy are the modest bunch who've dubbed themselves with the title of Language itself. I've learned much, I hope, from certain poets associated with Language poetics and techniques, and yet I find the gasps of mutual recognition and congratulation between Language poets and theoretically-inclined critics to be one of the more sick- 
ening and demoralizing spectacles in the recent annals of institutionalized poetry. Rarely has a "school" of poetics so embraced the concerns and even the vocabulary of the academy; Alan Golding's talk last night hinted, in a very different tone, at the fervor with which some Language poets have courted the approval of an academic establishment they claim to reject-so deeply felt is their persecuted sense of exclusion from the academy, despite the fact that they occupy a roughly proportional and ever-increasing share of academic positions, and that their work seems to have become the preoccupation of academic critics working on contemporary poetry. Language poetry is not the fault of very great poets like Olson and Duncan and Creeley or very good ones like Palmer and Scalapino and Hejinian and Perelman, each of whom is a fierce enough imaginative "presence," an original enough guarantor of his or her own "authorship," to have the word "Language" slide from their name-tags and write for and as themselves in the truly diverse world of poets. Fairly or unfairly, even where groups of likeminded individuals exist, individuals, not groups, write poems, and some individuals have more talent and more character than others. What the lesser lights, the middle managers of poetry in any guise, do, is say the right things, the appropriate things. In the case of Language poetry that has involved an adoption of not only the conceptual terms, but more paradoxically, the thematics, of theory, and the re-packaging of theory in forms that look like poems - at which point they are ready to be received, with a stunningly un-critical welcome, by academic critics.

There's a reason why a lot of poets, including some of the poets I've mentioned who are associated with the Language movement, scramble to resist the language of theory: by-and-large it's boring language, drained of expressive capacity, capable of uttering little more than the self-evident truths of theory that offer us comfort when we've forgotten how to feel.

My own critical bursting point was reached about ten years ago when I read Lyotard's essay “The Differend," which, as I remember, opens with a long examination of the troubled referential status of the Nazi genocide, and in particular of the linguistic and epistemological problem of the gas chambers. I know that Lyotard was not really offering intellectual legitimization to genocide-deniers; but I couldn't help but find it revealing that the most sophisticated 
forms of theoretical activity could so easily, and without much prodding, be put to this service. I developed a personal problem with the theoretical problem of reference. I think there's something wrong with the desire to "de-stabilize" the "real" out of existence. I think it's morally wrong and politically wrong and intellectually corrupt and I think it repeats the annihilating gestures of the very ideologies it attempts to critique and I think it's fearful and most of all I think it's untrue. The real may never have been "stable" but it has also never not been real, in some indeterminate way or other. I say this because I think that poems, which at best are un-theoretical acts, have always been the site of the mind's struggle with the real, in the quest to make the self more real, and the real more real, and the relationship between individual and social selves more real. For me, the further I moved from theory, over the years, the less my poems came to participate, knowingly at least, in discourses outside of themselves, the less they offered themselves up as translations of ideas received outside the poem. When I started writing journalism about five or six years ago, it was not only to escape the uncertainties, and certainties, of full-time academic life, but to put myself in the real, and force myself to contend with it, without theoretical armature. A few years ago in that capacity I went to Bangladesh when the country was eighty percent covered in flood waters. People lived on their roofs; people lived in water; people slogged through chest-high water running with sewage and their skin would be discolored with infections. Though Bangladesh is theorizable, there was nothing theoretical about it, and to me it is an abuse and an evasion not to struggle with, and defer to, the referentiality of Bangladesh. I talked to a man whose shanty in the port city of Chittagong had been buried the night before in a mud slide. His two children had died, and he survived. He was digging through the muck to try and retrieve his cooking utensils. I asked him what he thought when he lay covered in the mud, waiting to be rescued. And he said: I thought that God had left the world.

Now I'm going to read a poem, because poems know that the real is tenuous and that to enter into a relationship with the real is a hard and necessary thing to do. The poem, by William Bronk, is called "At Tikal": 
Mountains they knew, and jungle, the sun, the starsthese seemed to be there. But even after they slashed the jungle and burned it and planted the comforting corn, they were discontent. They wanted the shape of things. They imagined a world and it was as if it were there - a world with stars in their places and rain that came when they called. It closed them in. Stone by stone, as they built this city, these temples, they built this world. They believed it. This was the world, and they, of course, were the people. Now trees make up assemblies and crowd in the wide plazas. Trees climb the stupendous steps and rubble them. In the jungle, the temples are little mountains again.

It is always hard like this, not having a world, to imagine one, to go to the far edge apart and imagine, to wall whether in or out, to build a kind of cage for the sake of feeling the bars around us, to give shape to a world. And oh, it is always a world and not the world. 